\title{
Microbeam Analysis Society
}

doi: $10.1017 /$ S1431927608080537

\section{Message from the President}

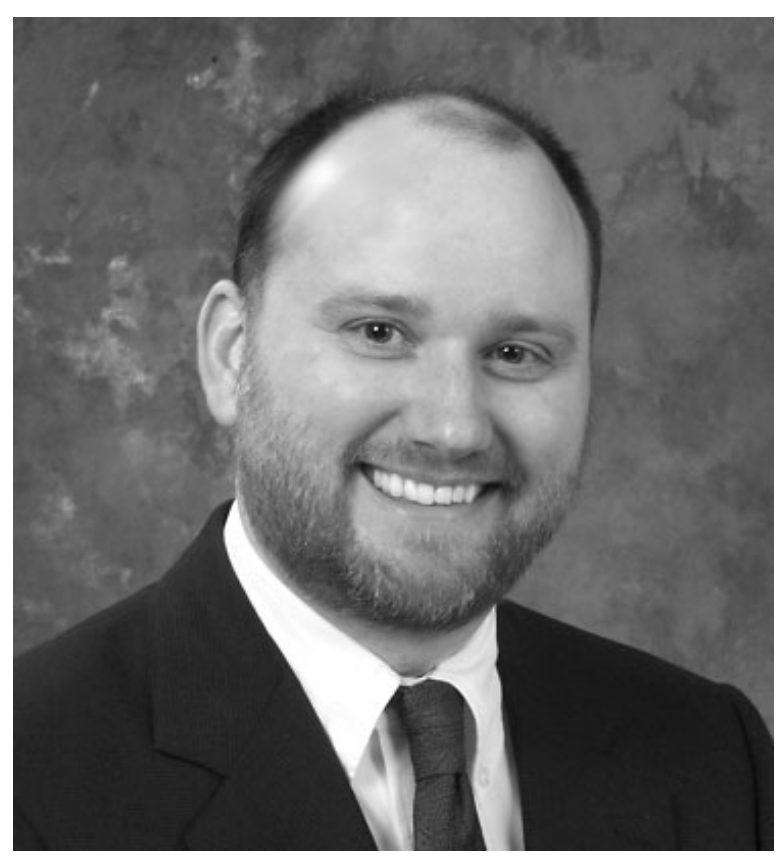

Ian M. Anderson

Microbeam Analysis Society

On behalf of the membership of the Microbeam Analysis Society (MAS), welcome to Microscopy and Microanalysis 2008, held August 3-7, 2008 in Albuquerque, NM. The Microscopy and Microanalysis (M\&M) meeting was established in 1996 as the joint annual meeting of the Microscopy Society of America (MSA) and MAS, and has served as the annual meeting of the International Metallographic Society (IMS) since 2002. I thank my counterparts in these societies, MSA President Bill Gunning and IMS President Dave Fitzgerald, with whom I've worked closely, for all their time and effort in putting together this meeting. I also welcome members of the International Society for Analytical Cytology (ISAC; J. Paul Robinson, President), which is sponsoring a substantial Pre-Meeting Congress during the weekend prior to M\&M 2008 and a symposium during the week.

Working with representatives of the Program Committee over the past months, I have been impressed with the extent to which the varied programming interests of the three joining societies have been fashioned into a single integrated program. I offer congratulations to MSA Program Chair John Henry Scott, MSA Vice-Chair Janet Woodward, MAS Co-Chair Paul Carpenter, and IMS Co-Chair Jaret Frafjord for this remarkable accomplishment. Thanks also to this year's Program Committee "Junta," and for the the annual efforts in the production of the program by Stuart McKernan and Nestor Zaluzec,

\section{MAS Calendar OF Events 2008}

Sunday, August 3, 2008

MAS Council Meeting (Ruidoso Room), 7:30 AM-5:30 PM

MAM Editors' Board Meeting (Zuni Room), 3:00-5:00 PM

Opening Reception, 6:30-9:30 PM (Rio Grande Zoo, ticket required, see Page 19)

Monday, August 4, 2008

MAM Editorial Board Meeting (Zuni Room), 7:15-8:15 AM

M\&M 2008 Program Planning Meeting (Zuni Room), 3:30-5:00 PM

\section{Tuesday, August 5, 2008}

M\&M 2009 Call for Papers Meeting (Zuni Room), 10:00 AM-12:00 PM

MAS Presidential Happening (Aztec Room), 12:15-1:15 PM

\section{Wednesday, August 6, 2008}

MAS Affiliated Regional Societies Luncheon

(Cochiti Room), 12:15-1:15 PM

MAS Business Meeting (Aztec Room), 5:15-6:15 PM

MAS Members Social, 6:30 PM

(ticket required; visit MAS Booth for information)

Thursday, August 7, 2008

MSA/MAS Sustaining Members Breakfast

(Tesuque Room), 7:00-9:00 AM

database gurus extraordinaire, EXPO Editor Richard Edelmann, and Proceedings Editor John Shields. The hospitality and local expertise of the Local Arrangements Committee, chaired by Joe Michael, have been instrumental in bringing together many aspects of the meeting. Finally, let me convey a warm welcome to Nicole Guy, our new meeting manager. Many of you will notice improvements during the week that are a result of Nicole's professional expertise.

One of my great honors of serving as society President is the bestowing of Distinguished Scholar Awards. This year's establishment of the Chodos Fund will help to bring students to the annual meeting for years to come. I hope that you will have the opportunity to attend several of the presentations given by this year's student award winners, whose research illustrates the breadth and quality of research that our society stands for. Please make an effort to meet them and invite them into the life of the Microbeam Analysis Society. 


\section{MAS COUNCIL Officers 2007}

\author{
Executive Council \\ President Ian M. Anderson \\ President Elect Catherine Johnson \\ Past President Paul G. Kotula \\ Secretary Scott D. Davila \\ Treasurer James J. McGee \\ Directors 2006-2008 \\ John H. Fournelle \\ Masashi Watanabe \\ 2007-2009 \\ Luke N. Brewer \\ Kristin L. Bunker \\ 2008-2010 \\ Stuart McKernan \\ Nicholas W. M. Ritchie
}

\author{
Appointed Officers and Committee Chairs \\ MAS Business Office William S. Thompson \\ 2005-2008 \\ Membership Services Louis M. Ross \\ Strategic Planning \\ Sustaining Members \\ Paul K. Carpenter \\ Catherine Johnson \\ 2006-2009 \\ Computer Activities Scott A. Wight \\ Education \\ Phillip E. Russell \\ International Liaison \\ MicroNews Editor \\ Joseph R. Michael \\ Ryna B. Marinenko \\ 2007-2010 \\ Affiliated Regional Societies Paul F. Hlava \\ Archivist \\ John H. Fournelle \\ Corporate Liaison Vernon E. Robertson \\ Finance
}

\section{MAS Past Presidents}

$\begin{array}{ll}1968 & \text { L. S. Birks } \\ 1969 & \text { K. F. J. Heinrich } \\ 1970 & \text { R. E. Ogilvie } \\ 1971 & \text { A. A. Chodos } \\ 1972 & \text { K. Keil } \\ 1973 & \text { D. R. Beaman } \\ 1974 & \text { P. Lublin } \\ 1975 & \text { J. W. Colby } \\ 1976 & \text { E. Lifshin } \\ 1977 & \text { J. I. Goldstein } \\ 1978 & \text { J. D. Brown } \\ 1979 & \text { D. F. Kyser } \\ 1980 & \text { O. C. Wells } \\ 1981 & \text { J. R. Coleman }\end{array}$

MAS Sustaining Members 4pi Analysis, Inc.

Advanced MicroBeam, Inc.

Bruker AXS Microanalysis

Cameca Instruments, Inc.

Carl Zeiss SMT

Denton Vacuum, LLC

EDAX, Inc.

Electron Microscopy Sciences/

Diatome US
Energy Beam Sciences, Inc.

FEI Company

Gatan, Inc.

Geller MicroÅnalytical Laboratory, Inc.

Hitachi High Technologies America, Inc.

IXRF Systems, Inc

JEOL USA, Inc.

Lehigh University

$\begin{array}{ll}1996 & \text { D. E. Johnson } \\ 1997 & \text { J. R. Michael } \\ 1998 & \text { R. B. Marineko } \\ 1999 & \text { J. J. Friel } \\ 2000 & \text { C. E. Lyman } \\ 2001 & \text { R. W. Linton } \\ 2002 & \text { G. P. Meeker } \\ 2003 & \text { E. S. Etz } \\ 2004 & \text { P. K. Carpenter } \\ 2005 & \text { I. H. Musselman } \\ 2006 & \text { R. Gauvin } \\ 2007 & \text { P. G. Kotula }\end{array}$

1996 D. E. Johnson

1998 R. B. Marineko

D. C. Joy

D. E. Newbury

C. G. Cleaver

C. E. Fiori

W. F. Chambers

D. B. Wittry

A. D. Romig, Jr.

J. T. Armstrong

D. B. Williams

T. G. Huber

J. A. Small

1995 J. J. McCarthy 


\section{MAS Awards}

Peter Duncumb Award for Excellence in Microanalysis The Duncumb Award recognizes outstanding achievement over a sustained period of time in the field of microanalysis through technical accomplishment, leadership, and educational and professional activities. The award winner is chosen through nomination by the MAS membership and selection by vote of MAS Council.

\section{Presidential Service Award}

This award honors a member of MAS for outstanding volunteer service to the society over a sustained period of time. The award winner is chosen annually by the MAS President.

\section{Presidential Science Award}

This award honors a senior scientist for outstanding technical contributions to the field of microanalysis over a sustained period of time. The award winner is chosen annually by the MAS President.

\section{K. F. J. Heinrich Award}

This award honors a scientist under the age of forty for distinguished technical contributions to the field of microanalysis. The award winner is chosen annually by the MAS President.

\section{MAS Distinguished Scholar Awards}

These awards are presented annually to students presenting high quality technical papers with significant microanalysis content at the annual meeting. The award is comprised of complimentary registration and significant funds to defray travel expenses to attend the meeting. Application is accomplished by requesting consideration for a student award during the paper submission process. Qualified applicants must be full-time students at an accredited educational institution, must be first author of the paper submitted for consideration, and must present the paper in person at the meeting. MAS Distinguished Scholars receive invitations to attend MAS-sponsored functions throughout the week of the annual meeting, including the Presidents' Reception and the MAS Social. The award winners are chosen annually by the MAS President.

\section{MAS Outstanding Paper Awards}

These awards are presented annually to the authors of outstanding papers from the previous annual meeting in each of four categories. The four awards are as follows:

- Birks Award, for best contributed paper;

- Macres Award, for best instrumentation or software paper;

- Cosslett Award, for best invited paper; and

- Castaing Award, for best student paper.

Candidates for the MAS Outstanding Paper Awards are nominated, through consultation with symposium organizers and the MAS membership, by the MAS Directors in their final year of service at the time of the meeting, then approved by vote of MAS Council. 


\section{Awards}

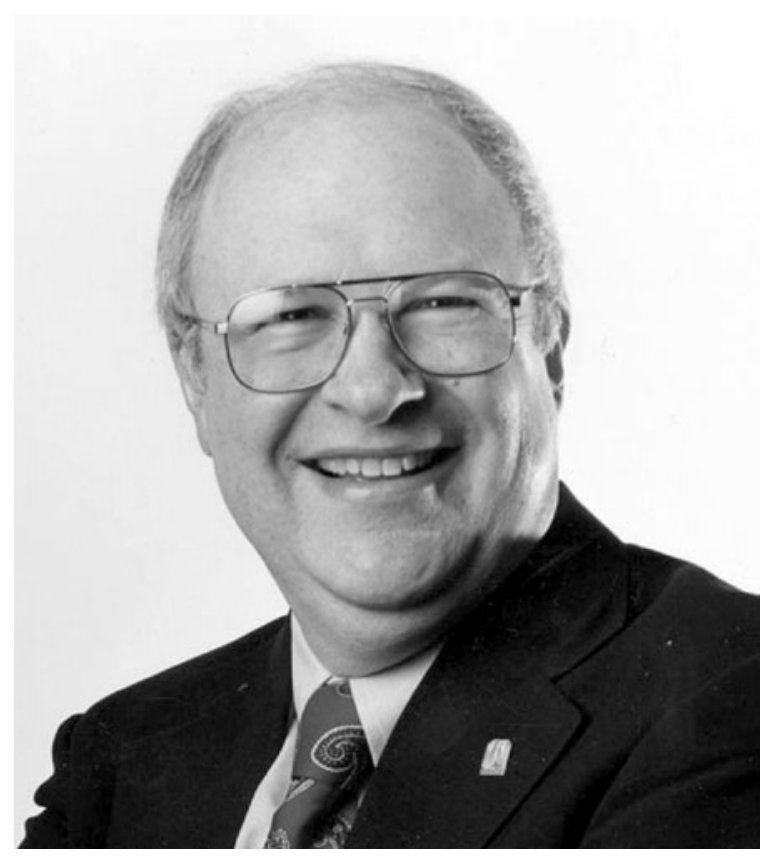

Duncumb Award for Excellence in Microanalysis Joseph I. Goldstein

Joseph I. Goldstein is a scientist, educator and administrator internationally known for his work in the development of $\mathrm{X}$-ray techniques in electron microscopy to determine the chemistry of small regions of solid materials, ranging from cubic micrometers to cubic nanometers, and in the field of meteoritics, the study of meteorites and other extraterrestrial materials. Working with colleagues, he has developed methodologies and instrumentation for electron microscopes to improve spatial resolution, to minimize the effects of spurious radiation, and to improve light element and trace element analysis, and used these techniques to measure diffusion coefficients and phase diagrams, to study phase growth and ternary diffusion effects in iron base alloys and various diffusion coatings, and to understand the metal phases in meteorites and lunar samples. Dr. Goldstein has written over 200 technical papers. He has been awarded the Presidential Science Award of the Microbeam Analysis Society and the Leonard Medal of the Meteoritical Society.

Joe Goldstein has shown active leadership in his fields of study. He founded the Lehigh Microscopy School, the most influential and comprehensive education program in electron microscopy and microanalysis, and has co-authored textbooks that have become the recognized standards in the field. As a university administrator, he has overseen the development of several major research centers, the improvement of undergraduate engineering curricula, and the promotion of information technology education. He has served as president of the Microbeam Analysis Society and The Meteoritical Society.

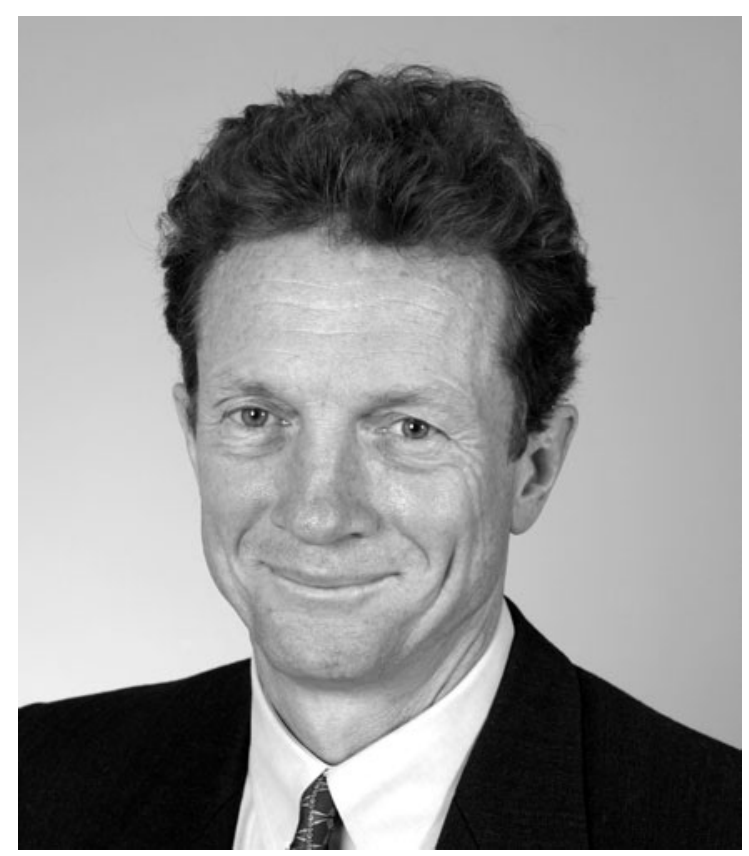

Presidential Science Award Thomas F. Kelly

Thomas F. Kelly, professor of Materials Science and Engineering at the University of Wisconsin-Madison until September 2001, founded Imago Scientific Instruments to commercialize the atom-probe microscope- a technology that enables researchers to analyze materials such as computer chips at the atomic scale. His invention, the Local Electrode Atom Probe (LEAP), captures an atom-by-atom "picture" of a material and renders that image on a computer screen in 3D.

Thomas F. Kelly received a B.Sc. in Mechanical Engineering with highest honors from Northeastern University in 1977 and a Ph.D. in Materials Science from the Massachusetts Institute of Technology in 1981. He joined the faculty of the University of Wisconsin-Madison in January 1983, becoming a Full Professor in 1994. Tom served as Director of the Materials Science Center from 1992 to 1999.

Tom Kelly has been active in the fields of microscopy and microanalysis, and their applications to rapidly solidified, electronic, and superconducting materials for over 30 years. He has published over 125 papers and 6 patents in these fields over this period. Dr. Kelly is an authority on microstructural characterization. He is expert in most methods and techniques of transmission electron microscopy, scanning electron microscopy, and atom probe microscopy and has brought innovations to their instrumentation and practice. Tom has served as a Director of the Microscopy Society of America. He is currently President of the International Field Emission Society. 


\section{Awards}

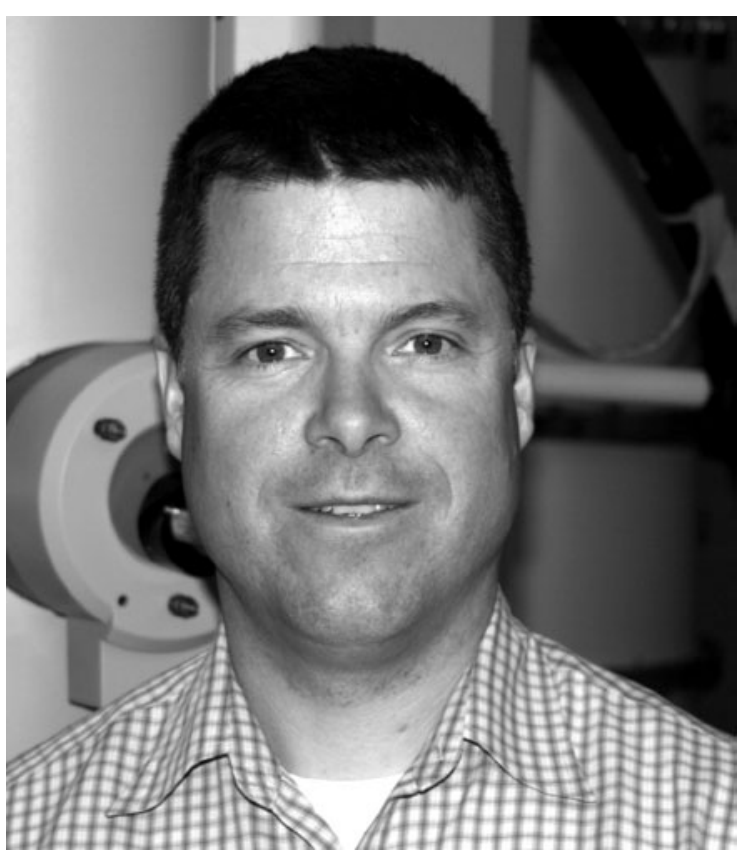

K. F. J. Heinrich Award Paul G. Kotula

Paul G. Kotula is a Principal Member of Technical Staff in the Materials Characterization Department at Sandia National Laboratories in Albuquerque, NM. Paul received his B.S. from Cornell University and Ph.D. from the University of Minnesota, both in Materials Science and Engineering. Before joining Sandia, he was a Director-Funded Postdoctoral Fellow at Los Alamos National Laboratory. His work at Sandia includes analytical electron microscopy support for microelectronic and micro-electromechanical device development, welding, brazing, soldering, forensics, process feedback, failure analysis, and 3D materials characterization and microanalysis. He is the Principal Investigator for a project for the Department of Homeland Security on the development of better analytical techniques for forensics and attribution of bio-weapon materials and has also helped build a world-renowned research program on acquisition and automated multivariate statistical analysis of spectral image data sets. The software developed from this work for $\mathrm{x}$-ray microanalysis is commercially available from Thermo Fisher Scientific and is now in over 200 labs worldwide. Paul's work has also garnered several awards over the years, among them an R\&D 100 Award in 2002, two MAS Outstanding Paper Awards (Macres, 2000; Birks, 2004), and two Best Analytical Techniques paper of the year in the society journal, Microscopy and Microanalysis $(2003,2006)$.

Paul has been an Adjunct Professor in the Department of Materials Science and Engineering at North Carolina State University since 2001 and has authored or co-authored over 50 journal articles on a wide variety of topics involving electron microscopy and microanalysis as well as two patents and two book chapters. His work has been featured on two journal covers and he has given over 10 invited/keynote presentations at international meetings and over 30 at domestic meetings.

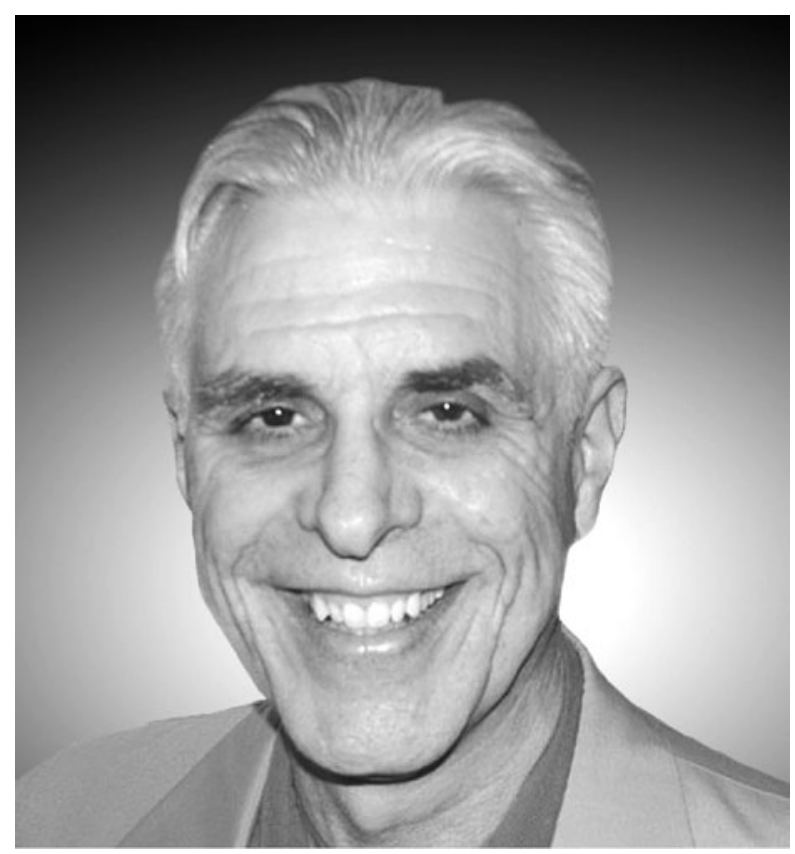

Presidential Service Award Louis M. Ross

Louis M. Ross is the Senior Electron Microscope Specialist in the Electron Microscopy Core Facility (EMCF) and Adjunct Instructor in the Department of Physics and Astronomy at the University of Missouri (MU) in Columbia. Lou received his Bachelors degree in Geology at Washington University in St. Louis in 1975. As an undergraduate research assistant during his senior year, he was introduced to scanning electron microscopy and X-ray microanalysis (SEM/EDS) in the McDonnell Center for the Space Sciences, where he remained as a research technician through 1982. In that year, Lou moved to MU to oversee the electron microprobe laboratory in the Department of Geological Sciences. In his years at $\mathrm{MU}$, he has overseen the consolidation of electron microscopy operations, culminating with the present EBCF in 2000. Lou now teaches two graduate courses in SEM/EDS at MU.

Lou Ross has had a strong record of involvement in Microbeam Analysis Society (MAS) and its affiliated regional societies (AReS) since he joined MAS in 1985. In 1990, he co-founded MIKMAS (Missouri, Illinois, and Kansas MAS) and ten years later helped to orchestrate its merger with another regional society, forming the Central States Microscopy and Microanalysis Society (CSMMS); he served two terms as President of both MIKMAS and CSMMS. Lou has served as MAS Membership Services Chair for the past ten years, during which time he has been instrumental in fostering communications between the MAS Council and its members along with interacting with the various MAS committees while overseeing all aspects of the membership operations. In 2008, he will begin a three-year term as MAS Sustaining Membership Chair. 


\section{MAS Distinguished Scholars}

P. Bajaj University of Texas at Dallas

Correlative Microscopic and Spectroscopic Characterization of Carboxylated Single-Walled Carbon Nanotubes

J. J. Cha Cornell University

Tunneling Magnetoresistance and B Diffusion in CoFeB/MgO/CoFeB Magnetic Tunnel Junctions Characterized by STEM-EELS

M. Eddy University of Michigan

Microbeam Analysis of Plasma Effects in Synthetic Mica-Like Compound

H. C. Floresca University of Texas at Dallas

New FIB Fold-Out Method for TEM Cross-Section Sample Preparation

B. R. Gipson University of California at Davis

$2 d x$-Automated 3D Structure Reconstruction from 2D Crystal Data

J. M. LeBeau University of California at Santa Barbara

Quantitative HAADF-STEM and EELS

B. McMorran University of Arizona

Very Low Energy TEM Diffraction of Nanostructures

W. D. Pyrz University of Delaware

Using Aberration-Corrected STEM Imaging to Explore Chemical and Structural Variations in the M1 Phase of the $\mathrm{MoVNbTeO}$ Oxidation Catalyst

W. Walkosz University of Illinois at Chicago

Investigation of the Atomic Structures of $\mathrm{Si}_{3} \mathrm{~N}_{4} / \mathrm{CeO}_{2-\delta}$ Interfaces using Atomic Resolution Z-Contrast Imaging and EELS Combined with First-Principles Methods

H. L. Xin Cornell University

Controlling Channeling Effects in Aberration-Corrected STEM Tomography

\section{Microbeam Analysis Society Outstanding Paper Awards from M\&M 2007}

\section{Birks Award-Best Contributed Paper}

S. D. Davilla; 4pi Analysis, Inc.

Event Streamed Spectrum Imaging (ESSI)

Macres Award-Best Instrumentation/Software Paper

R. P. Dougherty; OptiNav, Inc.; K.-H. Kunzelmann; Ludwig-Maximilians-Universität, Munich, Germany

Computing Local Thickness of 3D Structures with ImageJ

\section{Cosslett Award-Best Invited Paper}

S. Jesse, B. Rodriguez, A. P. Baddorf, S.V. Kalinin; Oak Ridge National Laboratory; M. Alexe; Max-Planck-Institut für MikrostrukturPhysik, Halle, Germany

Mapping the Nucleation and Growth of Ferroelectric Domains using Switching Spectroscopy Piezoresponse Force Microscopy

\section{Castaing Award-Best Student Paper}

H. Demers, R. Gauvin; McGill University, Canada

A General X-ray Fluorescence Correction for Electron Microanalysis by Monte Carlo Simulations 


\section{Previous Award Winners}

\section{Science}

$\begin{array}{ll}1977 & \text { R. Castaing } \\ 1978 & \text { K. F. J. Heinrich } \\ 1979 & \text { P. Duncumb } \\ 1980 & \text { D. B. Wittry } \\ 1981 & \text { S. J. B. Reed } \\ 1982 & \text { R. Shimizu } \\ 1983 & \text { J. Philibert } \\ 1984 & \text { L. S. Birks } \\ 1985 & \text { E. Lifshin } \\ 1986 & \text { R. L. Mykleburst } \\ 1987 & \text { O. C. Wells } \\ 1988 & \text { J. D. Brown } \\ 1989 & \text { J. Hillier } \\ 1990 & \text { T. E. Everhart } \\ 1991 & \text { J. I. Goldstein } \\ 1992 & \text { G. W. Lorimer } \\ & \text { G. Cliff } \\ 1993 & \text { D. E. Newbury } \\ 1994 & \text { D. C. Joy } \\ 1995 & \text { G. Bastin } \\ 1996 & \text { A. V. Somlyo } \\ 1997 & \text { D. P. Somlyo } \\ 1998 & \text { F. H. Williams } \\ 1999 & \text { R. A. Sareen } \\ 2000 & \text { R. F. Egerton } \\ 2001 & \text { P. E. Batson } \\ 2002 & \text { K. Keil } \\ 2003 & \text { P. E. Russell } \\ 2004 & \text { J. T. Armstrong } \\ 2005 & \text { G. Slodzian } \\ 2006 & \text { B. J. Griffin } \\ \text { R. D. Leapman } \\ \end{array}$

\section{Service}

1977

Lublin

D. R. Beaman

1979 M. A. Giles

1980 A. A. Chodos

1981 R. L. Myklebust

1982 J. Doyle

1983 D. E. Newbury

1984 J. I. Goldstein

1985 M. C. Finn

1986 V. Shull

1987 D. C. Joy

1988 C. G. Cleaver

1989 W. F. Chambers

1990 C. E. Fiori

1991 T. G. Huber

1992 E. S. Etz

1993 H. A. Freeman

1994 J. L. Worrall

1995 R. W. Linton

1996

1997

1998

1999

2000

2001

2002

2003

2004

2005

2006

2007
P. F. Hlava

J. A. Small

J. J. McCarthy

T. G. Huber

R. B. Marinenko

C. E. Lyman

J. F. Mansfield

I. H. Musselman

J. R. Michael

G. P. Meeker

H. A. Freeman

P. K. Carpenter
K. F. J. Heinrich

1986 P. J. Statham

1987 J. T. Armstrong

1988 D. B. Williams

1989 R. D. Leapman

1990 R. W. Linton

1991 A. D. Romig, Jr.

1992 S. J. Pennycook

1993 P. E. Russell

1994 J. R. Michael

1995 E. N. Lewis

1997 R. Gauvin

1998 V. P. Dravid

1999 J. Bruley

2000 H. Ade

2001 C. Jacobsen

2002 D. A. Wollman

2005 M. Watanabe

2006 M. Toth

2007 G. Kothleitner

\section{P. Duncumb}

2007 D. B. Williams 